\title{
IDENTIFICATION OF CYCLO(L-PRO-D-TYR) FROM BACILLUS AMYLOLIQUEFACIENS Y1 EXHIBITING ANTIFUNGAL ACTIVITY AGAINST FUSARIUM GRAMINEARUM TO CONTROL CROWN ROT IN WHEAT
}

\author{
JAMAL, Q. ${ }^{1,2^{*}}-$ MONKHUNG, S. ${ }^{3}-$ MUNIR, S. ${ }^{4}-$ CHO, J. Y. ${ }^{5}-$ MOON, J. H. ${ }^{6}-$ KHATTAK, B. U. ${ }^{2}-$ \\ MALIK, M. S. ${ }^{2}-$ YOUNIS, F. ${ }^{7}-$ KIM, K. Y. ${ }^{*}$ \\ ${ }^{1}$ Division of Food Technology, Biotechnology and Agrochemistry, Institute of Environmentally- \\ Friendly Agriculture, Chonnam National University, Gwangju 61186, South Korea \\ ${ }^{2}$ Department of Microbiology, Kohat University of Science and Technology, \\ Kohat, KP 26000, Pakistan \\ ${ }^{3}$ Crop Production Technology Program, Faculty of Animal Science and Agricultural \\ Technology, Silpakorn University, Phetchaburi Information Technology Campus, \\ Phetchaburi 76120, Thailand \\ ${ }^{4}$ Faculty of Plant Protection, Yunnan Agricultural University, \\ Kunming 650201, Yunnan, PR China \\ ${ }^{5}$ Department of Food Engineering, Mokpo National University, Mokpo, South Korea \\ ${ }^{6}$ Department of Food Science and Technology, BK21 Plus Program, Chonnam National \\ University, Gwangju 61186, Republic of Korea \\ ${ }^{7}$ Sulaiman Bin Abdullah Aba Al-Khail Centre for Interdisciplinary Research in Basic Sciences, \\ International Islamic University, Islamabad, Pakistan \\ *Corresponding authors \\ e-mail:qaiserjamal71@yahoo.com; kimkil@jnu.ac.kr \\ (Received $24^{\text {th }}$ Dec 2018 ; accepted $28^{\text {th }}$ Feb 2019)
}

\begin{abstract}
In this study, evidence for antagonism of antifungal metabolites produced by Bacillus amyloliquefaciens Y1 was described, as they actively inhibit growth of Fusarium graminearum under in vitro and in vivo condition. The culture supernatant and crude butanol extract inhibit the mycelial growth of $F$. graminearum. In addition, an antifungal compound was purified from the metabolites of $\mathrm{Y} 1$ and identified as cyclo(L-Pro-D-Tyr) using ${ }^{1} \mathrm{H}$ and ${ }^{13} \mathrm{C}$ NMR spectroscopic analysis. For the first time, cyclo (L-Pro-D-Tyr) displayed potent antifungal activity against $F$. graminearum under in vitro condition. The hyphae of this fungal pathogen became deformed with cyclo(L-Pro-D-Tyr). Exposure of $F$. graminearum to various concentrations of cyclo(L-Pro-D-Tyr) on wheat seeds significantly inhibit fungal colonization. Furthermore, during in vivo wheat pot experiment, Y1 results in 27\% higher total yield and showed a protective effect against $F$. graminearum by reducing low discoloration symptoms on stems. The grain yield per pot was five times higher compared to control pots (water only) infected with $F$. graminearum. To our knowledge, the antifungal activity of the cyclo(L-Pro-D-Tyr) is reported for the first time against the plant pathogenic fungus $F$. graminearum. The present study demonstrated the potential of $B$. amyloliquefaciens $\mathrm{Y} 1$ as a biocontrol agent against the wheat crown rot fungal pathogen as well as a plant growth promoter for wheat.
\end{abstract}

Keywords: biological control, wheat disease, chemistry, antifungal, pathogen 


\section{Introduction}

Two major destructive fungal diseases that posing a serious threat to wheat cultivation and production are head blight and crown rot caused by the mycotoxinproducing fungal pathogen Fusarium graminearum. Fusarium crown rot (FCR) is characterized by dry rot of crown, necrosis of root tissue and basal stem, and limited grain yield. Fusarium crown rot has never gotten much attention as it is mainly considered to be limited in its geological distribution, but according to latest reports, it occurs in many cereal producing regions (Smiley et al., 2005 a,b). A severe intensive infection can result in more than $50 \%$ yield loss, and reduced grain quality. It is known that this fungus is harmful to animals and humans because it produces several mycotoxins in wheat such as zearalenone (ZEA) (Cowger and Arellano, 2013) and deoxynivalenol (DON), that can cause embryotoxic, neurotoxic, immunosuppressive and teratogenic effects (Cowger and Arellano, 2013; Pestka, 2007; Pestka and Smolinski, 2005).

Conventional methods such as crop rotation and inter-row sowing can be used to control diseases caused by $F$. graminearum. Crop rotation is effective, but there are also economic limitations, as $F$. graminearum can reside inside the stubble for several years (Burgess, 2005). The recent reports revealed that there is a remarkable reduction in the Fusarium crown rot (FCR) damage due to inter-row sowing (Simpfendorfer et al., 2012). Due to limitations, FCR has recently been reported in cereal-growing regions. Moreover, chemical management is effective but the application of chemicals such as acephate, carbendazin, chlorothalonil, chlopyriphos, Dichlorodiphenyltrichloroethane (DDT), and diazinon causes environmental pollution, affects human health, and enables pathogens to build resistance to these chemicals (Baldwin and Rathmell, 1988). Few studies have been done about the losses caused by $F$. graminearum and more information is needed to manage this pytopathogenic fungus through the application of antagonistic microorganisms (Palazzini et al., 2016).

Several bacteria are available commercially including strains of the genera Pseudomonas and Bacillus, and have been used successfully as alternative to chemical pesticides in crop production (Choudhary and Johri, 2009). Bacillus species are among the most important bacteria that can be most promising for plant protection (PérezGarcía et al., 2011). Their most notable characteristics include their ability to survive for extended periods of time, their spore formation, the wide range of biochemically active molecules that can significantly inhibit phytopathogen growth and ease of formulating their commercial products (Broggini et al., 2005). Bacillus subtilis, Bacillus amyloliquefaciens and Paenibacillus polymyxa mostly found in soil are considered to be safe for use in environment and with mammals (Stabb et al., 1994; Zhao et al., 2015). Two new cyclic lipopeptides (3 and 4) were isolated from the culture filtrate of Bacillus amyloliquefaciens strain SD-32, together with two known metabolites, iso-C15 and isoC16 bacillomycin D (Tanaka et al., 2014). They can provide higher protection to plants (Falcäo et al., 2014; Krebs et al., 1993), because of their antifungal and antibacterial activities against several phytopathogens (Ben Abdallah et al., 2015; Krebs et al., 1998). They produce various types of secondary metabolites (antibiotics) (Asaka and Shoda, 1996; Stabb et al., 1994) and most of them have been identified as low molecular weight dipeptide or cyclic peptides (Dolej and Bochow, 1996; Nakano and Zuber, 1990; Vanittanakom et al., 1986). Among cyclic peptides, diketopiperazines (DKPs) are relatively simple cyclic dipeptides consisting of two $\alpha$-amino acids produced by bacteria, fungi, mammals, and plants (Ström et al., 2002). 
More attention has paid to study about diversity and biological roles of more than 100 DKPs found in nature (McCleland et al., 2004). Four DKPs from B. thuringiensis strain and two from $B$. endophyticus demonstrated their antifungal activities (Sansinenea et al., 2016). Beside their antimicrobial properties, cyclic peptides are involved in root colonization and the systemic stimulation of immune system of the host plant (Ongena and Jacques, 2008). In general, the activities of cyclic peptides from Bacillus spp. against fungal phytopathogens have been frequently described. Synthetic DKPs has also been reported to have antibacterial and antifungal activities (Graz, 2002; Pitchen, 2002).

The present study was aimed to evaluate antifungal potential of B. amyloliquefaciens Y1 against $F$. graminearum under in vitro and in vivo condition. In addition, identification of an antifungal compound may have a role in its probable mechanism to control Fusarium crown rot in wheat.

\section{Materials and methods}

\section{Microorganisms and culture conditions}

B. amyloliquefaciens Y1 was isolated previously with accession number KP967704. Fusarium graminearum KACC 41040, was obtained from Korea Agriculture Culture Collection (KACC). For in vitro and in vivo study, a spore suspension was prepared by growing $F$. graminearum in carboxymethyl cellulose (CMC) broth at $25^{\circ} \mathrm{C}$ in shaking incubator for 10 days.

\section{Antifungal characterization}

\section{Antifungal activity of culture supernatant}

Antifungal activities were detected by growing strain $\mathrm{Y} 1$ in Luria-Bertani 33 (Palazzini et al., 2016) broth at $40{ }^{\circ} \mathrm{C}$ for 7 days at $170 \mathrm{rpm}$. The culture broth was centrifuged at $7,000 \times \mathrm{g}$ for $20 \mathrm{~min}$. The supernatant collected was filtered through Whatman filter paper No. $2(0.45 \mu \mathrm{m})$ and finally with $0.20 \mu \mathrm{m}$ syringe filter. The resulting supernatant was mixed with sterile PDA to make final concentration of 0,10 , 30 , and $50 \%$. A $5 \mathrm{~mm}$ diameter mycelial plug of $F$. graminearum from a 7-days-old culture was placed in the centre of the PDA plate and incubated at $28{ }^{\circ} \mathrm{C}$ in the dark. Mycelial growth was measured as colony diameter of $F$. graminearum hyphae after 6 days inoculation and growth inhibition percentage were evaluated by using the following formula:

$$
\text { Growth inhibition percentage }(\mathrm{GI} \%)=[(\mathrm{R}-\mathrm{r}) / \mathrm{R}] \times 100
$$

where $\mathrm{R}$ is the radius/ diameter of the colony on the control plates and $\mathrm{r}$ is the radius of the colony on the treatment plate. Experiment was carried out in triplicate and repeated three times.

\section{Antagonistic activity of bacterial crude extract against the plant pathogens}

Strain Y1 was inoculated into the LB broth at $40{ }^{\circ} \mathrm{C}$ for 10 days. The $\mathrm{pH}$ of $\mathrm{Y} 1$ culture broth was adjusted to 3 using concentrated $\mathrm{HCl}$ and used to obtain the crude extract by active fractionation $(1: 1, \mathrm{vol} / \mathrm{vol})$ with an eluotropic series of solvents: ethyl 
acetate and n-butanol. The partially isolated butanol solvent was concentrated through a rotary evaporator to get crude extract (48 g) (Büchi, Rheinstetten, Germany). A 20\% stock solution of crude extract was prepared. From the stock solution, 3, 4 and $5 \mathrm{mg}$ was added on paper disc to check antifungal activity against $F$. graminearum. A $5 \mathrm{~mm}$ diameter mycelial plug from 7 days old culture was placed in the centre of the PDA plate. The control consists of an equal volume of methanol added to another paper disc on the same PDA plate. Mycelial growth was measured as colony diameter of $F$. graminearum and growth inhibition was evaluated by using the following formula:

$$
(\mathrm{GI} \%)=[(\mathrm{R}-\mathrm{r}) / \mathrm{R}] \times 100
$$

where $\mathrm{R}$ is the radius/diameter of the fungal growth towards the paper disc on the control side and $r$ is the radius of the fungal colony growth towards the paper disc on the treatment side. Experiment was carried out in triplicate.

\section{Extraction and purification of the antifungal compound}

The butanol crude extract ( $48 \mathrm{~g}$ ) was prepared from cell free culture supernatant (36 L) of strain Y1 and was dissolved in methanol and subjected to silica gel column chromatography (Kieselgel 60, 70-230 mesh, Merk, Darmstadt, Germany) with stepwise elution of $\mathrm{CHCl}_{3}: \mathrm{MeOH}(100: 0,90: 10,70: 30,40: 60,50: 50$, and 0:100; v/v). Total of 3L solvent was used in each step of elution. The vacuum (EYELA rotary vacuum evaporator) was used to concentrate all fractions to a semisolid mass, and each fraction was assayed for antifungal activity. The bioactive fraction $\mathrm{CHCl}_{3}: \mathrm{MeOH}$ (100:0) was further purified by HPLC (high-performance liquid chromatography) using a system with a PrepHT C18 column $(7 \times 300 \mathrm{~mm}, 10 \mu \mathrm{m})$. The SPD-10 UV-VIS detector (Shimadzu, Japan) was used to monitor elution with manual injection at 210 and $254 \mathrm{~nm}$ using acetonitrile and water as a mobile phase (35:65) at a flow rate of $2 \mathrm{~mL} / \mathrm{min}$. All peaks were collected and concentrated using a centrifugal evaporator (Hanil Scientific Inc, South Korea) at $40{ }^{\circ} \mathrm{C}$. The purities of the collected fractions were further analysed using an HPLC analytical C18 column $(5 \mu \mathrm{L}, 4.6 \times 250 \mathrm{~mm})$. The pure compound with a single peak was used for antifungal activity. The active compound was used for further structural analysis.

\section{Identification of the purified antifungal compound}

The ${ }^{1} \mathrm{H}$ and ${ }^{13} \mathrm{C}$ nuclear magnetic resonance (NMR) was used to determine the structure of the purified compound. Briefly, the purified antifungal compound (approx. $12 \mathrm{mg}$ ) was dissolved in $0.6 \mathrm{~mL}$ methanol- $d 4\left(\mathrm{CD}_{3} \mathrm{OD}\right)$ and used for spectral analysis. NMR spectra were recorded on a DRX 500 NMR instrument (Bruker, Rheinstetten, Germany) operating at $500 \mathrm{MHz}$ for ${ }^{1} \mathrm{H}$ and $125 \mathrm{MHz}$ for ${ }^{13} \mathrm{C}$ at room temperature. Chemical shifts are reported in ppm $(\delta)$ using $\mathrm{CD}_{3} \mathrm{OD}$ as the solvent (unless otherwise indicated) and tetramethylsilane $\left.\left(\mathrm{CH}_{3}\right)_{4} \mathrm{Si}\right)$ as an internal standard.

Determination of antifungal activity of the purified compound and its effect on hyphal deformation

The purified compound was assayed against $F$. graminearum growth. A $4 \%$ stock solution of the purified compound was prepared in methanol. A total of $1000 \mu \mathrm{L}$ (a mixture of $300 \mu \mathrm{L}$ conidial suspension $+700 \mu \mathrm{L}$ CMC broth) was added to each well of 
a 24-well microplate except for the first well, which contained $600 \mu \mathrm{L}$ of the conidial suspension of $F$. graminearum $\left(4 \times 10^{6}\right.$ spores $\left./ \mathrm{mL}\right)$ and $1300 \mu \mathrm{L}$ CMC. After addition of the conidial suspension, $100 \mu \mathrm{L}$ of the compound was added to the first well. Further, serial dilution was performed to obtain the desire concentration of 2000, 1000, 500, 250, $125,62.5,31.25,15.625,7.81,3.90$, and $1.95 \mathrm{ppm}$ in each well. The conidial suspension of $F$. graminearum and methanol were used as a control. The well plate was kept for one $\mathrm{h}$ in clean bench to evaporate methanol. The direct effect of the antifungal compound on hyphae was examined using light microscope (Olympus BX41TF, Japan).

\section{Assessment of the purified compound to control F. graminearum on wheat seeds}

Wheat seeds $(\mathrm{n}=30)$ per treatment were immersed in $100 \mathrm{~mL}$ of $\mathrm{DW}$ (distilled water) for $1 \mathrm{~h}$, followed by immersing $1 \mathrm{~min}$ in a dilute solution of $\mathrm{NaOCl}$ (sodium hypochlorite) for surface sterilization. They were then washed with distilled water and placed in petri dish to dry. Solutions of the purified compound at various concentration were prepared in methanol using serial dilution to obtain serial doses $(2000,1000,500$, $250,125,62.5,31.25 \mathrm{ppm})$. Then, wheat seeds were soaked for $1 \mathrm{~h}$ in various concentration of compound and left in open petri dish to evaporate excess methanol. Seeds soaked in methanol were used as a control. A spore suspension of $F$. graminearum was prepared $\left(4 \times 10^{6}\right.$ spores $\left./ \mathrm{ml}\right)$ and approximately $10 \mu \mathrm{l}$ of the spore suspension was spread on each wheat seed. The inoculated wheat seeds were incubated at $28{ }^{\circ} \mathrm{C}$ on moisten cotton in petri dish, and the inhibition of fungal growth was recorded as white mycelia appeared on all seeds $(30=100 \%)$ in the control treatment. All tests were performed in triplicate.

\section{Glasshouse experiment}

The growth promotion and biocontrol effect of strain Y1 in wheat plants were also focused. Two types of pot experiment were performed in a greenhouse at Chonnam national university, South Korea. A glasshouse potting mix was prepared by mixing soil, sand, vermiculite, and compost at a ratio of 2:1:1:0.04 (v/v), respectively. The soil was air-dried and ground to pass through a $2-\mathrm{mm}$ sieve and mixed thoroughly. The potting mixture was transferred to $20 \mathrm{~L}$ pots containing $20-25 \mathrm{~kg}$ soil. A total 60 seeds per pot were sown in four rows. In one type of pot experiment, at two weeks interval, after 14,28, and 42 days of seeds sowing, each pot was amended by pouring $300 \mathrm{ml}$ of water, or fertilizer media (M) $\left(\mathrm{KH}_{2} \mathrm{PO}_{4} 0.08 \mathrm{~g}, \mathrm{KCl}(0-0-60) 0.02 \mathrm{~g}, \mathrm{~K}_{2} \mathrm{SO}_{4} 0.1 \mathrm{~g}, \mathrm{CaCl}_{2}\right.$ $0.1 \mathrm{~g}$, water soluble fertilizer $2.66 \mathrm{ml}$, blue fertilizer (20-20-20-2, $4 \mathrm{~g})$ per litre of water) or $\mathrm{Y} 1$ culture grown for 7 days at $40^{\circ} \mathrm{C}$ in media known as $\mathrm{BB}$ media (chitin $0.5 \mathrm{~g}$, gelatin $0.5 \mathrm{~g}$, Yeast $0.1 \mathrm{~g}, \mathrm{KH}_{2} \mathrm{PO}_{4} 0.08 \mathrm{~g}, \mathrm{KCl}(0-0-60) 0.02 \mathrm{~g}, \mathrm{~K}_{2} \mathrm{SO}_{4} 0.1 \mathrm{~g}, \mathrm{CaCl}_{2}$ $0.1 \mathrm{~g}$, water soluble fertilizer $2.66 \mathrm{ml}$, blue fertilizer (20-20-20-2, $4 \mathrm{~g}$ ) and sugar $4 \mathrm{~g} / \mathrm{L}$ of water) for a total of three times. The treatments were arranged in a randomized complete block design and replicated four times. To assess growth promotion in wheat, plant height, plant weight, root weight and grains per pot was calculated after four months.

To assess the biocontrol of crown rot in wheat by Y1, pots were amended with $F$. graminearum in the soil. One month after seed sowing, one $\mathrm{mL}$ of $F$. graminearum suspension containing $4 \times 10^{6}$ spores per $\mathrm{mL}$ was drench in each seedling. At 14, 28 and 42 days after seeds sowing, each pot was amended by pouring $300 \mathrm{~mL}$ of water $(\mathrm{C}+\mathrm{Fg})$, or fertilizer media $(\mathrm{M}+\mathrm{Fg})$, or strain $\mathrm{Y} 1$ culture grown in $\mathrm{BB}$ media 
$(\mathrm{Y} 1+\mathrm{Fg})$ or commercial fungicide $(\mathrm{F}+\mathrm{Fg})$. A total of 60 wheat tillers were randomly collected from each replicate after harvesting and assessed for the incidence of crown rot by recording the percentage of tillers with brown discoloration on the lower stems (Liu and Ogbonnaya, 2015). After harvesting the plants, reduction in yield due to crown rot was also measured by measuring plant height, plant weight/pot, root weight, and grains weight/pot.

\section{Statistical analysis}

The data were statistically analysed through SAS 9.1 software (SAS Institute, 2003). The least significant difference (LSD) was used to calculate mean values among treatments at a $5 \%$ level $(\mathrm{p}=0.05)$ of significance.

\section{Results}

\section{Antifungal characterization}

The cell-free culture supernatant displayed antifungal activity at various concentrations mixed in PDA as it inhibited the growth of $F$. graminearum. The inhibitory effects increased with concentration increased (Fig. 1a). At $10 \%$ concentration, the cell-free culture supernatant showed more than $30 \%$ growth inhibition of $F$. graminearum. Higher concentration increased the growth inhibition, as 40 and $45 \%$ growth inhibition were recorded for the 30 and $50 \%$ concentration, respectively.

The paper disc method assessed the antifungal effect of the bacterial $n$-butanol crude extract. The Y1 crude extract at various concentrations had good inhibition effect on the pathogenic fungi (Fig. 1 b). The crude extract $(3 \mathrm{mg}$ ) affected the growth of the tested fungi by $13 \%$. An increase in the inhibitory effect was found as the amount of treatment increased. The highest growth inhibition rates of $20 \%$ and $17 \%$ were obtained when 5 $\mathrm{mg}$ and $4 \mathrm{mg}$ of crude extract were added to the paper disc respectively. The antifungal compound-enriched extract revealed interesting antifungal activities.
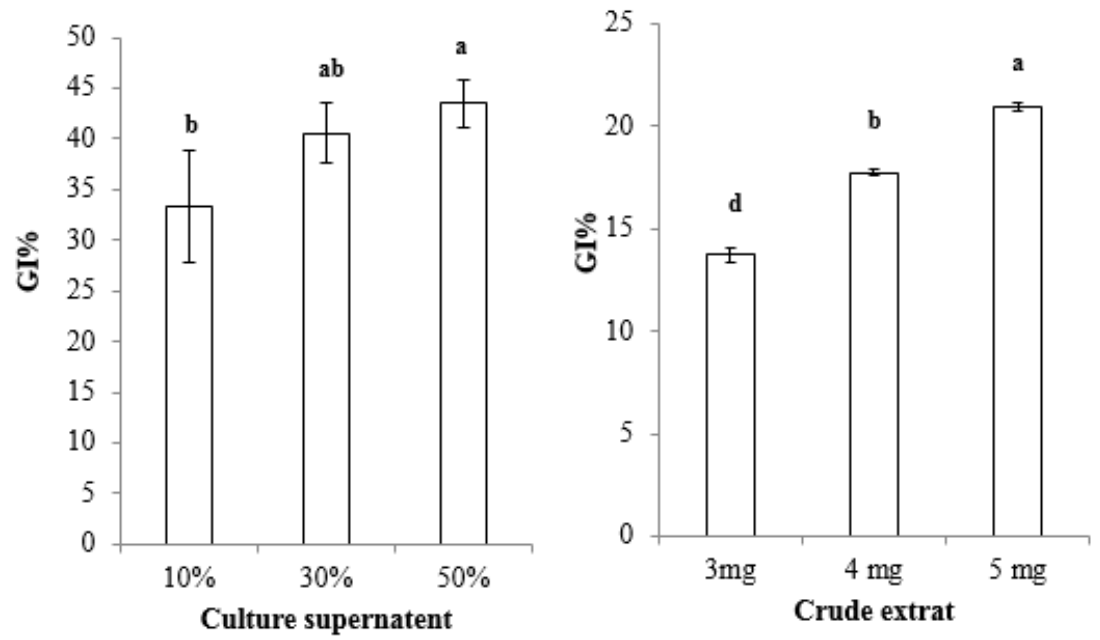

Figure 1. Effect of $Y 1$ culture filtrate (a) at various concentrations on growth of $F$. graminearum. Effect of different crude extracts $(b)$ concentration of $Y 1$ on growth of $F$. graminearum. Calculated mean in chart values are from three replicates. Error bars represent standard deviation of mean 


\section{Extraction and purification of antifungal compound}

The Y1 crude extract displayed antifungal activity against $F$. graminearum according to paper disc assay. A bioactive fraction was found because of silica gel column chromatography. The bioactive fraction $(2 \mathrm{~g})$ was further subjected to prep HPLC. The purity of the compound was confirmed with a single peak on an analytical HPLC column (Fig. 2). The antifungal activity of pure compound was checked and confirmed by testing against $F$. graminearum using paper disc method. The $12 \mathrm{mg}$ of pure active compound obtained from $n$-butanol crude extract of Y1 strain. The bioactive antifungal compound showed a single peak with a 4.93 min retention time.

\section{$<$ Chromatogram $>$}

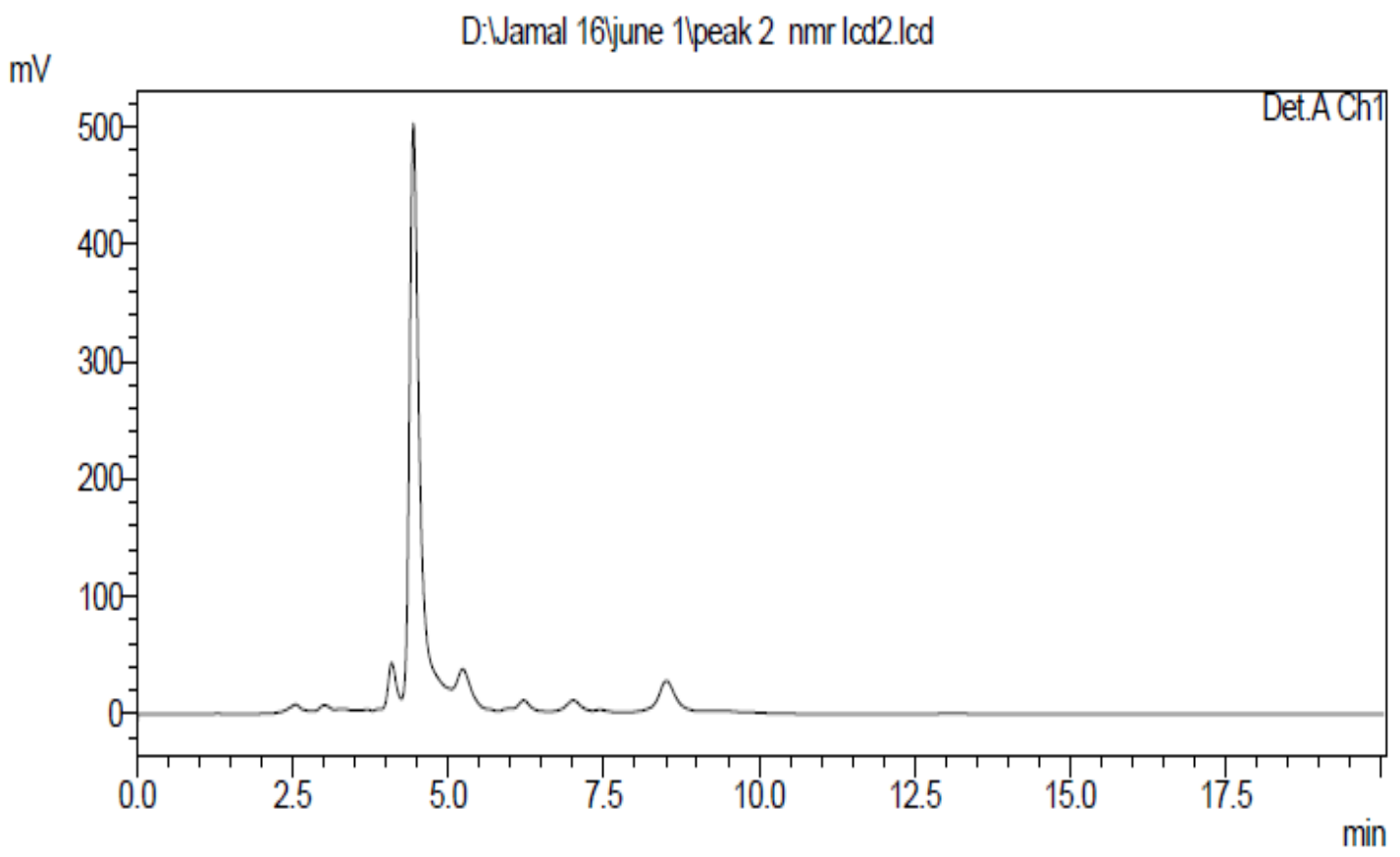

Figure 2. The high-performance liquid chromatography (HPLC) spectrum of the purified antifungal compound from strain $Y 1$

\section{Identification of the purified antifungal compound}

The structure of the purified antifungal compound was identified according to its ${ }^{1} \mathrm{H}$ and ${ }^{13} \mathrm{C}-\mathrm{NMR}$ spectra (Fig. $3 a$ and $b$ ). Peak data were as follows. ${ }^{1} \mathrm{H}$ NMR $(500 \mathrm{MHz}$, $\left.\mathrm{CD}_{3} \mathrm{OD}, \delta, J / \mathrm{Hz}\right): 4.37(1 \mathrm{H}, \mathrm{dt}, 5.0,2.0, \mathrm{H}-2), 2.11(1 \mathrm{H}, \mathrm{m}, \mathrm{H}-4 \mathrm{a}), 1.80(1 \mathrm{H}, \mathrm{m}, \mathrm{H}-4 \mathrm{~b})$, 2.09 (1H, m, H-5a), 1.82 (1H, m, H-5b), 3.49-3.61(1H, m, H-6), 7.04 (2H, d, 8.5, H$\left.2^{\prime}, 6^{\prime}\right), 6.71\left(2 \mathrm{H}, \mathrm{d}, 8.5, \mathrm{H}-3^{\prime}, 5^{\prime}\right), 3.06(1 \mathrm{H}, \mathrm{ddd}, 11.0,6.5,1.0, \mathrm{H}-7 \mathrm{a}), 4.05$ (1H, ddd, 11.0, 6.5, 2.0, H-8'), ${ }^{13} \mathrm{C}-\mathrm{NMR}\left(125 \mathrm{MHz}, \mathrm{CD}_{3} \mathrm{OD}\right): \delta \mathrm{C}(\mathrm{ppm}) 170.8(\mathrm{C}-1), 60(\mathrm{C}-2)$, 46.062 (C-3), 29.4 (C-4), 37.831 (C-5), 45.9 (C-6), 127.6 (C-1'), 132.1 (C-2',6'), 116.2 $\left(\mathrm{C}-3^{\prime}, 5^{\prime}\right), 157.7\left(\mathrm{C}-4^{\prime}\right), 37.7(\mathrm{C}-7), 57.9\left(\mathrm{C}^{\prime} 8^{\prime}\right)$ and 167 (C-9'). From the NMR spectra, the compound was identified as cyclo(L-Pro-D-Tyr) (Fig. 4). The NMR spectrum was found to be similar to that reported by Kumar et al. (2013a). 

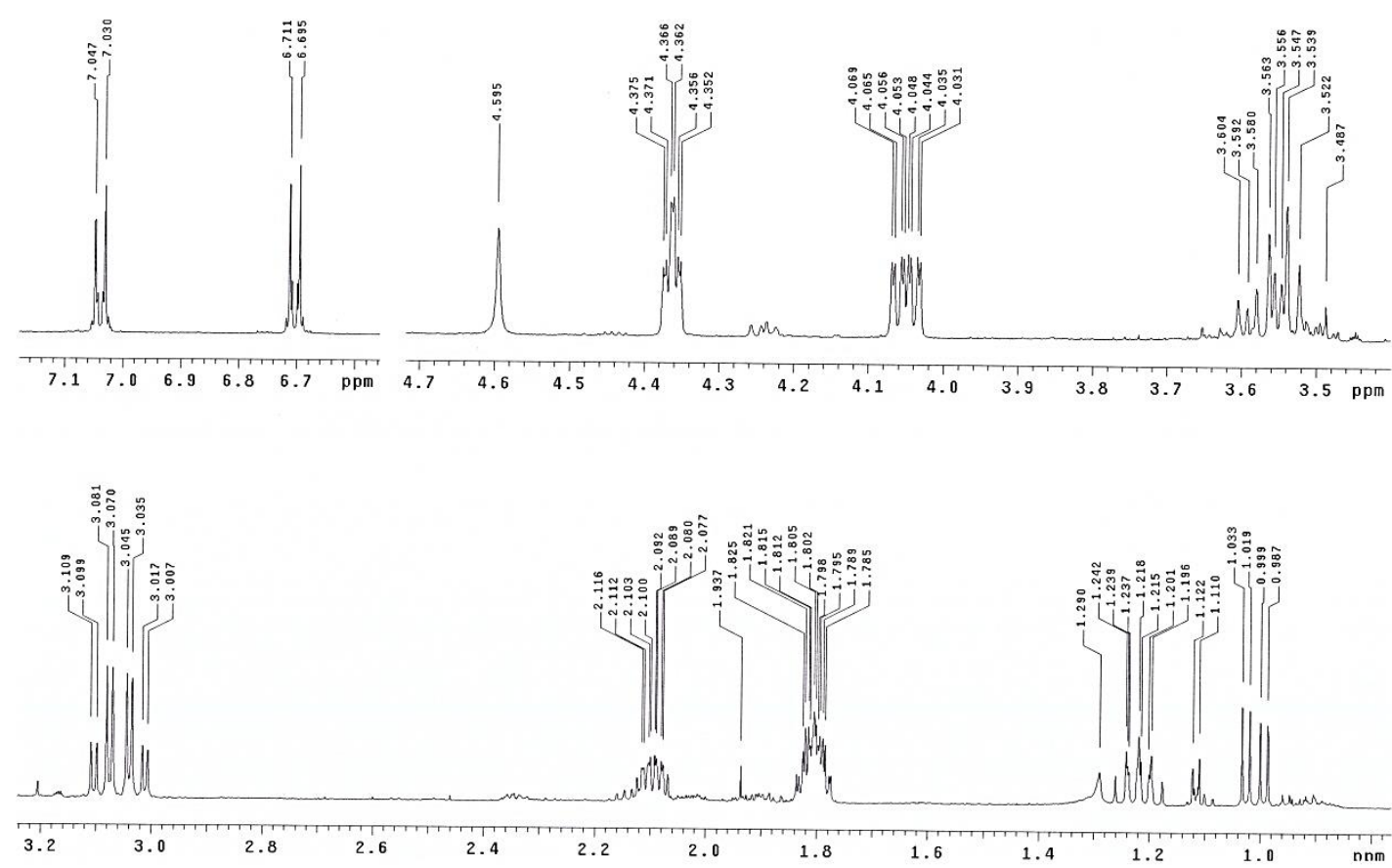

b

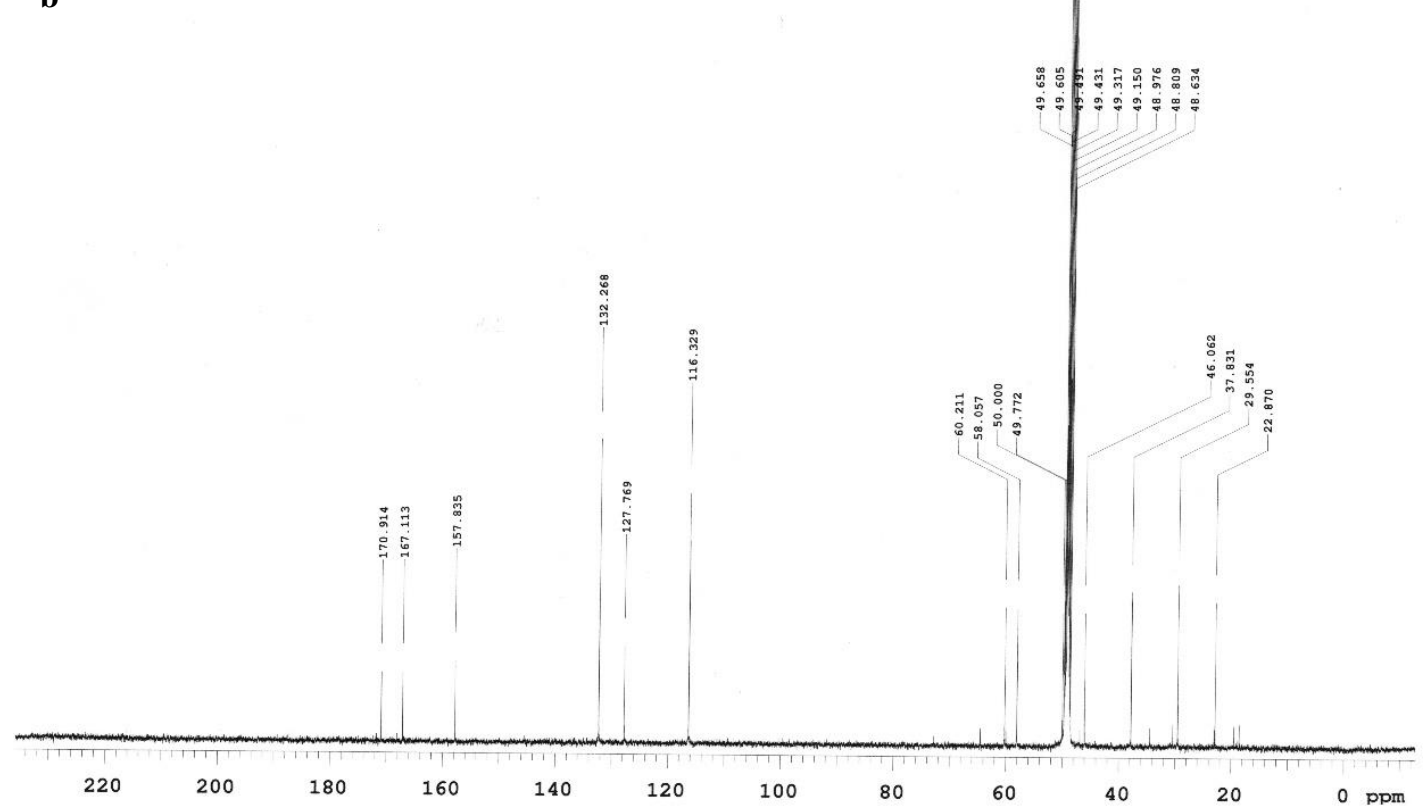

Figure 3. ${ }^{1} \mathrm{H}(\mathrm{a})$ and ${ }^{13} \mathrm{C}(\mathrm{b})$ nuclear magnetic resonance (NMR) spectra of the purified antifungal compound cyclo(L-Pro-D-Tyr) from strain YI

\section{Determination of antifungal activity of the purified compound and its effect on fungal} hyphae

Antifungal activity assay showed that various concentration of cyclo(L-Pro-D-Tyr) inhibited growth of $F$. graminearum, as evidenced by decreasing turbidity in wells with increasing treatments concentration. Microscopic examination revealed that the hyphae of $F$. graminearum were altered because of the cyclo(L-Pro-D-Tyr) treatment. The results clearly highlight that $125 \mathrm{ppm}$ affected the mycelia growth of $F$. graminearum, 
and the effects increased with increasing concentration of compound: at $250 \mathrm{ppm}$ and $500 \mathrm{ppm}$, there was more visible hyphae deformation. Alterations in the shape, including deformation and degradation of hyphae, were observed under light microscopy (Fig. 5).

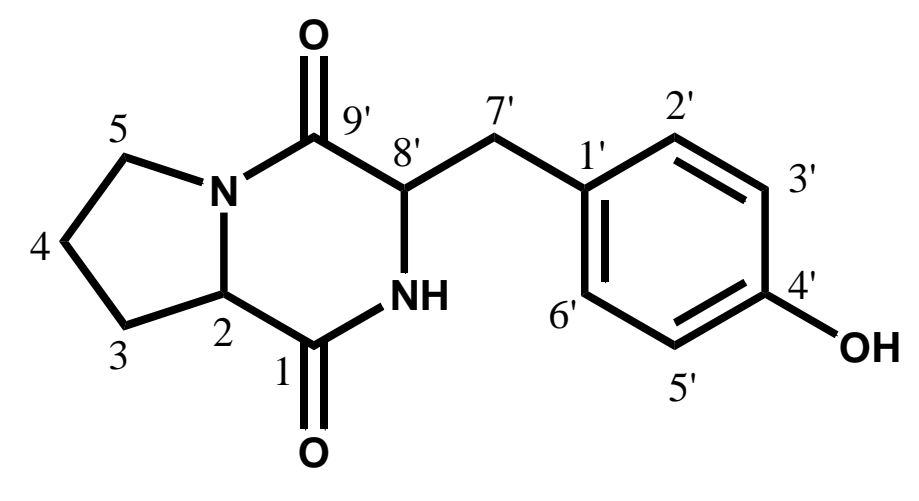

$$
\mathrm{C}_{14} \mathrm{H}_{16} \mathrm{~N}_{2} \mathrm{O}_{3}
$$

Exact Mass: 260.1161

$$
\text { cyclo(L-Pro-D-Tyr) }
$$

Figure 4. The structure of purified compound cyclo(L-Pro-D-Tyr) from strain Y1
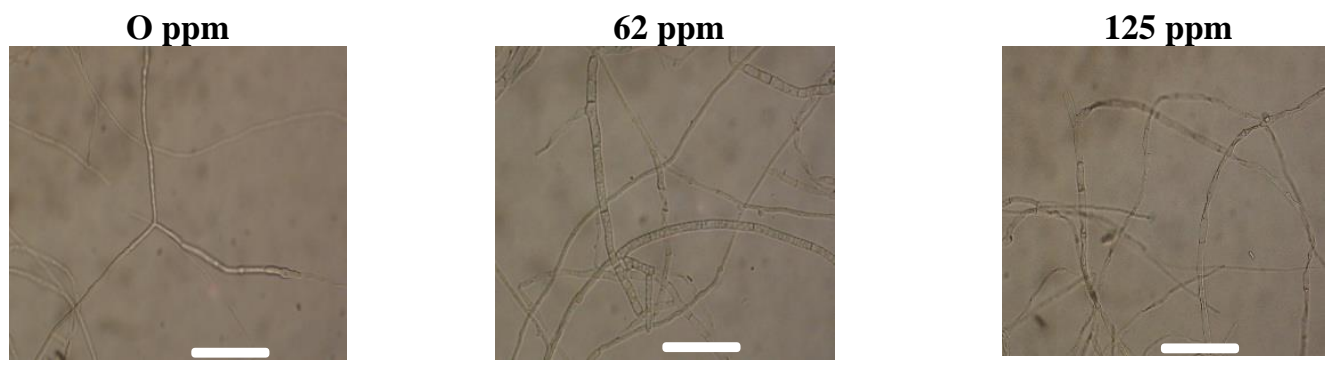

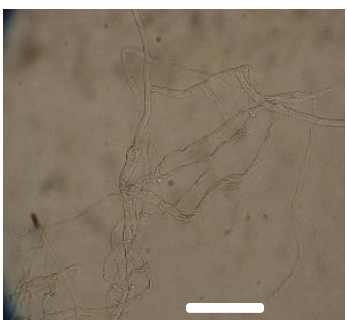

$250 \mathrm{ppm}$

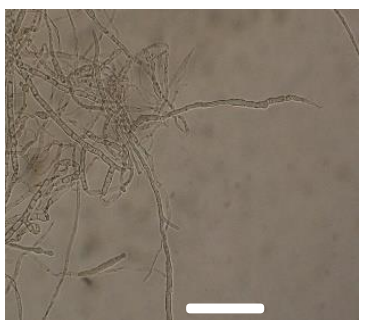

$500 \mathrm{ppm}$

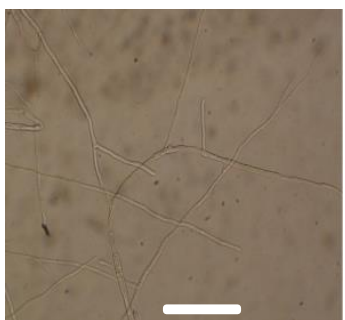

Methanol

Figure 5. Microscopically evident of changes in hyphae morphology of $F$. graminearum when treated with cyclo(L-Pro-D-Tyr). The carboxy methyl cellulase (CMC) containing $F$. graminearum conidial suspension only as control 0, 62, 125, 250, 500 ppm of Cyclo (L-Pro-DTyr) and methanol incubated for 5 days at $30^{\circ} \mathrm{C}$. All bars $=100 \mu \mathrm{m}$

\section{Assessment of the purified compound to control F. graminearum on wheat seeds}

The ability of secondary metabolites of strain Y1 to inhibit the growth of $F$. graminearum on wheat seeds would be of major concern to the agricultural economy. Thus, the ability of cyclo(L-Pro-D-Tyr) produced by strain Y1 to protect wheat seeds 
from diseases caused by $F$. graminearum was investigated. Wheat seeds soaked in various concentration of cyclo(L-Pro-D-Tyr) demonstrated marked delay and inhibited seeds colonization compared to the control (Fig. 6). White mycelia were observed in the control wheat seeds 2 days after fungal inoculation, whereas seeds treated with $125 \mathrm{ppm}$ or more of cyclo(L-Pro-D-Tyr) were found with low or no fungal growth.

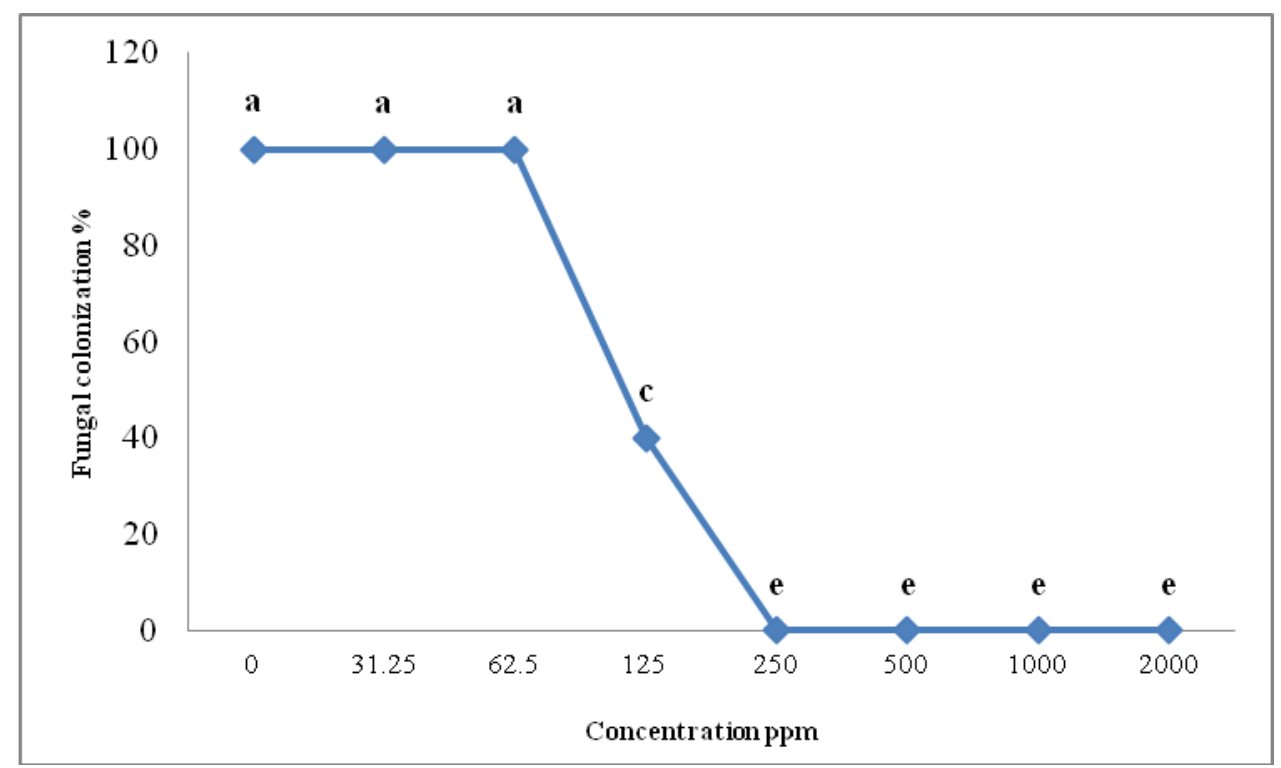

Figure 6. F. graminearum colonization on wheat seeds with various concentration of cyclo( $L$ Pro-D-Tyr). Means with the same letter are not significantly different at $P=0.05$ when compared by LSD

\section{Glasshouse experiment}

The plant growth-promoting ability of strain Y1 was assessed in vivo using pot experiment with fertilizer media and bacterial inoculum. The results obtained from the pot experiment are shown in Table 1. The results indicated that at four months after sowing seeds, there were significant differences between the control and strain Y1 treatments. For vegetative growth, total yield significantly improved with the application of strain Y1, as the plant height, weight and root weight were higher with the Y1 treatment. Strain Y1 also caused an increase in the reproductive growth of wheat. The numbers of grains per spike were significantly higher in strain Y1-treated pots compared to all other treatments.

In the biocontrol of FCR, strain Y1 was found to reduce the percentage of disease in plant. The results showed that harvesting plants after four months, the strain Y1 group had the higher plant stand average against crown rot (Table 1). Pots treated with strain Y1 displayed high values for plant height, plant weight, root weight, and total grains per pot due to the better response of the plants to the effects of $F$. graminearum in the soil. $F$. graminearum exhibited crown rot symptoms in the control and reduced wheat yield, as the $\mathrm{C}$ (without $F$. graminearum) had higher values for plant height, plant weight, root weight, and total grains per pot compared to $\mathrm{C}+\mathrm{Fg}$ (with $F$. graminearum spores) (Table 1). The level of control of crown rot in the pots treated with fertilizer medium was significantly lower (55\%) compared to the pots treated with strain Y1 (28\%). Total 
grain weight per pot increased with the application of medium (40 g) compared to the control only C + Fg ( $9 \mathrm{~g})$ but was lower compared to the application of strain Y1 (48 g).

Table 1. Effect of Y1 culture on crown rot severity of wheat in glass house experiment

\begin{tabular}{c|c|c|c|c|c}
\hline Treatment & $\begin{array}{c}\text { Disease } \\
\text { incidence \% }\end{array}$ & $\begin{array}{c}\text { Plant height } \\
\text { (cm) }\end{array}$ & $\begin{array}{c}\text { Plant } \\
\text { weight/pot (g) }\end{array}$ & Root weight (g) & $\begin{array}{c}\text { Grains } \\
\text { weight/pot (g) }\end{array}$ \\
\hline $\mathrm{C}$ & $\mathrm{NR}$ & $61.6 \mathrm{ab}$ & $71 \mathrm{bc}$ & $1.13 \mathrm{~b}$ & $21 \mathrm{c}$ \\
$\mathrm{Y} 1$ & $\mathrm{NR}$ & $67.4 \mathrm{a}$ & $174 \mathrm{a}$ & $1.64 \mathrm{a}$ & $68 \mathrm{a}$ \\
$\mathrm{M}$ & $\mathrm{NR}$ & $61.5 \mathrm{ab}$ & $148 \mathrm{ab}$ & $1.21 \mathrm{~b}$ & $42 \mathrm{~b}$ \\
$\mathrm{C}+\mathrm{Fg}$ & $65 \mathrm{a}$ & $49.1 \mathrm{~b}$ & $37 \mathrm{~d}$ & $0.98 \mathrm{bc}$ & $9 \mathrm{~d}$ \\
$\mathrm{Y} 1+\mathrm{Fg}$ & $28 \mathrm{c}$ & $64.24 \mathrm{a}$ & $148 \mathrm{ab}$ & $1.52 \mathrm{a}$ & $48 \mathrm{ab}$ \\
$\mathrm{M}+\mathrm{Fg}$ & $55 \mathrm{~b}$ & $56.1 \mathrm{a}$ & $126 \mathrm{~b}$ & $0.93 \mathrm{c}$ & $40 \mathrm{~b}$ \\
$\mathrm{~F}+\mathrm{Fg}$ & $8 \mathrm{~d}$ & $66.6 \mathrm{a}$ & $137 \mathrm{ab}$ & $1.03 \mathrm{bc}$ & $42 \mathrm{ab}$ \\
\hline
\end{tabular}

Means with the same letter are not significantly different at $\mathrm{P} \leq 0.05$ when compared by LSD

$\mathrm{NR}=$ Not Recorded, $\mathrm{C}=$ Water control, $\mathrm{Y} 1=$ Bacillus amyloliquefaciens $\mathrm{Y} 1$ culture, $\mathrm{M}=$ Fertilizer medium, $\mathrm{C}+\mathrm{Fg}=\mathrm{Water}+F$. graminearum, $\mathrm{Y} 1+\mathrm{Fg}=B$. amyloliquefaciens $\mathrm{Y} 1+F$. graminearum, $\mathrm{M}+\mathrm{Fg}=$ Fertilizer medium $+F$. graminearum, $\mathrm{F}+\mathrm{Fg}=$ Fungicide $+F$. graminearum

\section{Discussion}

In in vitro study, the culture supernatant and crude extract of B. amyloliquefaciens Y1 indicated fungicidal activity against $F$. graminearum. The increase in concentration of culture supernatant and crude extract displayed more growth inhibition. Several studies have reported that antagonistic bacteria showed antifungal properties by producing secondary metabolites in their culture broth against pathogens (Blin et al., 2013; Ehteshamul-Haque and Ghaffar, 1993; Liu et al., 2017). Increase in concentration of secondary metabolites produced by $B$. amyloliquefaciens Y1 were likely involve in increases activity (Jamal et al., 2015).

Recently, natural products have been investigated to report biocontrol mechanism of antagonistic microorganisms. In this study, we purified and identified cyclo(L-Pro-DTyr) as natural antifungal product from the culture supernatant of $\mathrm{Y} 1$ based on ${ }^{1} \mathrm{H}$ and ${ }^{13} \mathrm{C}$-NMR spectra. To our knowledge, this is the first report of cyclo(L-Pro-D-Tyr) from B. amyloliquefaciens strain as an antifungal compound. Cyclo(L-Pro-D-Tyr) is a diketopiperazine (DKP) compound (De Rosa et al., 2003) previously purified from body fluids, sponges, microorganisms, and a variety of tissues (Rudi et al., 1994; Ström et al., 2002). Cyclo(L-Pro-D-Tyr) has been isolated from Callyspongia sp., a specie of marine sponge in the South China Sea (Huang et al., 2010). Kumar et al. identified cyclo(LPro-D-Tyr) in the secondary metabolites of Bacillus spp. and reported its antifungal and antibacterial properties (Kumar et al., 2013a).

Both synthetic and natural DKPs displayed biological activities, including antiviral (Sinha et al., 2004), antifungal (Houston et al., 2004), antitumor (Nicholson et al., 2006) and antibacterial (Kwon et al., 2000). The antimicrobial activities of cyclo(L-Pro-DTyr) has been less explored; however, here we reported its antifungal activity against $F$. graminearum. The bio-preservative properties of the cyclo(L-Pro-D-Tyr) was also evaluated on growth suppression of $F$. graminearum on wheat seeds. To the best of our knowledge, there is no previous report of DKP cyclo(L-Pro-D-Tyr) to be used as biopreservative to report antagonistic mechanism to control $F$. graminearum causing foliar disease on wheat seeds. The bio-preservative property of DKP, cyclo(L-Pro-D-Leu) to 
inhibit growth of A. flavus and A. niger on soybeans was also reported (Kumar et al., 2013b). Previously, we identified cyclo(D-Pro-L-Val) in Y1 as antifungal metabolites against $F$. graminearum (Jamal et al., 2017). Bacillus subtilis L1-21 was also reported to control this pathogen in vitro (Munir et al., 2018). These findings showed that Y1 could control wheat foliar disease by producing DKPs and other antifungal metabolites.

The effectiveness of strain Y1 under in vivo condition was also evaluated for growth promotion of wheat plants and reduction in wheat crown rot. It has also been reported that many strains of $B$. subtilis, B. amyloliquefaciens, and B. cereus interact with plants and suppress plant pathogens (Choudhary and Johri, 2009; Jamal et al., 2017). Pseudomonas fluorescens LY1-8 was also reported to control the FHB and FCR in greenhouse and field (Wang et al., 2015). Application of Chlonostachys rosea ACM941 $\left(10^{8} \mathrm{cfu} / \mathrm{ml}\right)$ reduced the disease index in wheat by $30-46 \%$ (Xue et al., 2014b). The wheat stalks with several Fusarium species was successfully control with Clonostachys rosea (Palazzini et al., 2013). Moreover, biocontrol species of Chlonostachys suppress the disease on maize debris (Luongo et al., 2005), soybean debris and wheat, (Xue et al., 2014a) and floral crops (Morandi et al., 2008).

Bacteria suppress disease by producing a number of antibiotics (Nelson et al., 2014; Roitman et al., 1990; Xu et al., 2018). Cyclic dipeptides were reported to influence the quorum sensing signalling and has strong inhibitory effect against Vibrio anguillarum (Campbell et al., 2009; Fdhila et al., 2003; Yan et al., 2004). Similarly, our in vitro study demonstrated that cyclo(L-Pro-D-Tyr) act as an antibiotic to suppress growth of $F$. graminearum. The production of cyclo(L-Pro-D-Tyr) as an antifungal compound by $\mathrm{Y} 1$ in its culture broth may partially explain its biocontrol mechanism in wheat pot experiment. The production of cyclic peptides responsible for antimicrobial activity of the B. licheniformis N1 strain in the control of tomato gray mold, tomato late blight, and pepper anthracnose were also investigated (Kong et al., 2010). The biocontrol of Fusarium dry rot in wounded potato tubers is due to an antibiotic, pyrrolnitrin, produced by B. cepacia in its culture broth (Burkhead et al., 1994).

The strain Y1 not only control wheat crown rot but also improve plant growth, as evidenced by increase in plant weight, plant height, and grain yield per pot. The present study agree with the findings of Huang and Wong that Burkholderia cepacia (A3R) reduced wheat crown rot significantly in under glasshouse and field condition and increase grain yield (Huang and Wong, 1998). Many plant-growth promoting bacteria improve plant growth by producing antimicrobial compounds (Sopheareth et al., 2013; Xu et al., 2018). Briefly, the current and our previous study (Jamal et al., 2017) provides enough evidence to consider Y1 strain as a promising biocontrol agent to control FHB and FCR in wheat by producing antifungal DKPs cyclo(L-Pro-D-Tyr) and cyclo(D-ProL-Val) in its culture broth.

\section{Conclusions}

In conclusion, isolation of DKP cyclo(L-Pro-D-Tyr) from B. amyloliquefaciens Y1, is a new finding in biocontrol literature with its antifungal characterization against $F$. graminearum. Both in vitro and in vivo study resulted that application of $\mathrm{Y} 1$ suppressed growth of $F$. graminearum. Cyclo(L-Pro-D-Tyr) isolated from Y1 can serve as a role model to uncoil the antagonistic mechanism of biocontrol agent. In pot experiment, addition of Y1 significantly inhibited pathogen growth and enhanced wheat plant growth. Thus, our result indicated that $\mathrm{Y} 1$ can serve as successful substitute over 
synthetic chemicals which are detrimental to control pathogenic fungi causing serious health and environmental concerns. In addition, these biocontrol agents may serve as a potential antagonist to manage other important wheat diseases in the greenhouse and fields.

Acknowledgements. This research was supported by IPET (Institute of Planning and Evaluation for Technology in Food, Agriculture, Forestry and Fisheries for which this work was funded under grant no: 316032-5), Ministry for Food, Agriculture, Forestry and Fisheries, Republic of Korea.

\section{REFERENCES}

[1] Asaka, O., Shoda, M. (1996): Biocontrol of Rhizoctonia solani damping-off of tomato with Bacillus subtilis RB14. - Applied and Environmental Microbiology 62: 4081-4085.

[2] Baldwin, B., Rathmell, W. (1988): Evolution of concepts for chemical control of plant disease. - Annual Review of Phytopathology 26: 265-283.

[3] Ben Abdallah, D., Frikha-Gargouri, O., Tounsi, S. (2015): Bacillus amyloliquefaciens strain $32 \mathrm{a}$ as a source of lipopeptides for biocontrol of Agrobacterium tumefaciens strains. - Journal of Applied Microbiology 119: 196-207.

[4] Blin, K., Medema, M. H., Kazempour, D., Fischbach, M. A., Breitling, R., Takano, E., Weber, T. (2013): antiSMASH 2.0-a versatile platform for genome mining of secondary metabolite producers. - Nucleic Acids Research 41: W204-W212.

[5] Broggini, G., Duffy, B., Holliger, E., Schärer, H.-J., Gessler, C., Patocchi, A. (2005): Detection of the fire blight biocontrol agent Bacillus subtilis BD170 (Biopro ${ }^{\circledR}$ ) in a Swiss apple orchard. - European Journal of Plant Pathology 111: 93-100.

[6] Burgess, L. (2005): Intermediate hosts and the management of crown rot and head blight. Annual Report of GRDC Strategic Initiative on Crown Rot, Common Root Rot and Fusarium Head Blight. - Grains Research and Development Corporation, Kingston, Australia, pp. 34-36.

[7] Burkhead, K. D., Schisler, D. A., Slininger, P. J. (1994): Pyrrolnitrin production by biological control agent Pseudomonas cepacia B37w in culture and in colonized wounds of potatoes. - Applied and Environmental Microbiology 60: 2031-2039.

[8] Campbell, J., Lin, Q., Geske, G. D., Blackwell, H. E. (2009): New and unexpected insights into the modulation of LuxR-type quorum sensing by cyclic dipeptides. - ACS Chemical Biology 4: 1051-1059.

[9] Choudhary, D. K., Johri, B. N. (2009): Interactions of Bacillus spp. - and plants - with special reference to induced systemic resistance (ISR). - Microbiological Research 164: 493-513.

[10] Cowger, C., Arellano, C. (2013): Fusarium graminearum infection and deoxynivalenol concentrations during development of wheat spikes. - Phytopathology 103: 460-471.

[11] De Rosa, S., Mitova, M., Tommonaro, G. (2003): Marine bacteria associated with sponge as source of cyclic peptides. - Biomolecular Engineering 20: 311-316.

[12] Dolej, S., Bochow, H. (1996): Studies of the Mode of Action of Bacillus Subtilis Culture Filtrates in the Model Pathosystem Tomato Seedling-Fusarium Oxysporum f. sp. RadicisLycopersici. - Mededelingen-Faculteit Landbouwkundige en Toegepaste Biologische Wetenschappen Universiteit, Gent (Belgium).

[13] Ehteshamul-Haque, S., Ghaffar, A. (1993): Use of rhizobia in the control of root rot diseases of sunflower, okra, soybean and mungbean. - Journal of Phytopathology 138: 157-163.

[14] Falcäo, L., Silva-Werneck, J., Vilarinho, B., da Silva, J., Pomella, A., Marcellino, L. (2014): Antimicrobial and plant growth-promoting properties of the cacao endophyte Bacillus subtilis ALB629. - Journal of Applied Microbiology 116: 1584-1592. 
[15] Fdhila, F., Vázquez, V., Sánchez, J. L., Riguera, R. (2003): dd-Diketopiperazines: Antibiotics active against Vibrio a nguillarum isolated from marine bacteria associated with cultures of pecten $m$ aximus. - Journal of Natural Products 66: 1299-1301.

[16] Graz, C. J. M. (2002): Cyclic dipeptides as novel antimicrobial agents. http://hdl.handle.net/20.500.11892/156232

[17] Houston, D. R., Synstad, B., Eijsink, V. G., Stark, M. J., Eggleston, I. M., Van Aalten, D. M. (2004): Structure-based exploration of cyclic dipeptide chitinase inhibitors. - Journal of Medicinal Chemistry 47: 5713-5720.

[18] Huang, R.-M., Ma, W., Dong, J.-D., Zhou, X.-F., Xu, T., Lee, K. J., Yang, X., Xu, S.-H., Liu, Y. (2010): A new 1: 4-diazepine from South China Sea marine sponge Callyspongia species. - Molecules 15: 871-877.

[19] Huang, Y., Wong, P. (1998): Effect of Burkholderia (Pseudomonas) cepacia and soil type on the control of crown rot in wheat. - Plant and Soil 203: 103-108.

[20] Jamal, Q., Lee, Y. S., Jeon, H. D., Park, Y. S., Kim, K. Y. (2015): Isolation and biocontrol potential of Bacillus amyloliquefaciens Y1 against fungal plant pathogens. Korean Journal of Soil Science and Fertilizer 48: 485-491.

[21] Jamal, Q., Cho, J.-Y., Moon, J.-H., Munir, S., Anees, M., Kim, K. Y. (2017): Identification for the First Time of Cyclo (d-Pro-l-Leu) Produced by Bacillus amyloliquefaciens Y1 as a nematocide for control of Meloidogyne incognita. - Molecules 22: 1839.

[22] Kong, Q., Shan, S., Liu, Q., Wang, X., Yu, F. (2010): Biocontrol of Aspergillus flavus on peanut kernels by use of a strain of marine Bacillus megaterium. - International Journal of Food Microbiology 139: 31-35.

[23] Krebs, B., Junge, H., Ockhardt, A., Hoding, B., Heubner, D., Erben, U. (1993): Bacillus subtilis-an effective biocontrol agent. - Pesticide Science 37: 427-433.

[24] Krebs, B., Höding, B., Kübart, S., Workie, M. A., Junge, H., Schmiedeknecht, G., Grosch, R., Bochow, H., Hevesi, M. (1998): Use of Bacillus subtilis as biocontrol agent. I. Activities and characterization of Bacillus subtilis strains/Anwendung von Bacillus subtilis als Mittel für den biologischen Pflanzenschutz. I. Aktivitäten und Charakterisierung von Bacillus subtilis-Stämmen. - Zeitschrift für Pflanzenkrankheiten und Pflanzenschutz/Journal of Plant Diseases and Protection 105(2): 181-197.

[25] Kumar, N., Mohandas, C., Nambisan, B., Kumar, D. S., Lankalapalli, R. S. (2013a): Isolation of proline-based cyclic dipeptides from Bacillus sp. $\mathrm{N}$ strain associated with rhabitid entomopathogenic nematode and its antimicrobial properties. - World Journal of Microbiology and Biotechnology 29: 355-364.

[26] Kumar, S. N., Mohandas, C., Nambisan, B. (2013b): Purification of an antifungal compound, cyclo (L-Pro-D-Leu) for cereals produced by Bacillus cereus subsp. thuringiensis associated with entomopathogenic nematode. - Microbiological Research 168: 278-288.

[27] Kwon, O. S., Park, S. H., Yun, B.-S., Pyun, Y. R., Kim, C.-J. (2000): Cyclo (DehydroalaL-Leu), an. ALPHA.-Glucosidase Inhibitor from Penicillium sp. F70614. - The Journal of Antibiotics 53: 954-958.

[28] Liu, C., Ogbonnaya, F. C. (2015): Resistance to F. usarium crown rot in wheat and barley: a review. - Plant Breeding 134: 365-372.

[29] Liu, K., Newman, M., McInroy, J. A., Hu, C.-H., Kloepper, J. W. (2017): Selection and assessment of plant growth-promoting rhizobacteria for biological control of multiple plant diseases. - Phytopathology 107: 928-936.

[30] Luongo, L., Galli, M., Corazza, L., Meekes, E., Haas, L. D., Van Der Plas, C. L., Köhl, J. (2005): Potential of fungal antagonists for biocontrol of Fusarium spp. in wheat and maize through competition in crop debris. - Biocontrol Science and Technology 15: 229242.

[31] McCleland, K., Milne, P., Lucieto, F., Frost, C., Brauns, S., Venter, M., Plessis, J., Dyason, K. (2004): An investigation into the biological activity of the selected 
histidine-containing diketopiperazines cyclo (His-Phe) and cyclo (His-Tyr). - Journal of Pharmacy and Pharmacology 56: 1143-1153.

[32] Morandi, M. A., Mattos, L. P., Santos, E. R., Bonugli, R. C. (2008): Influence of application time on the establishment, survival, and ability of Clonostachys rosea to suppress Botrytis cinerea sporulation on rose debris. - Crop Protection 27: 77-83.

[33] Munir, S., Li, Y., He, P., He, P., He, P., Cui, W., Wu, Y., Li, X., He, Y. (2018): Bacillus subtilis L1-21 possible assessment of inhibitory mechanism against phytopathogens and colonization in different plant hosts. - Pakistan Journal of Agricultural Sciences 55(4): 996-1002.

[34] Nakano, M. M., Zuber, P. (1990): Molecular biology of antibiotic production in Bacillus. - Critical Reviews in Biotechnology 10: 223-240.

[35] Nelson, B. A., Ramaiya, P., de Leon, A. L., Kumar, R., Crinklaw, A., Jolkovsky, E., Crane, J. M., Bergstrom, G. C., Rey, M. W. (2014): Complete genome sequence for the Fusarium head blight antagonist Bacillus amyloliquefaciens strain TrigoCor 1448. Genome Announcements 2: e00219-00214.

[36] Nicholson, B., Lloyd, G. K., Miller, B. R., Palladino, M. A., Kiso, Y., Hayashi, Y., Neuteboom, S. T. (2006): NPI-2358 is a tubulin-depolymerizing agent: in-vitro evidence for activity as a tumor vascular-disrupting agent. - Anti-Cancer Drugs 17: 25-31.

[37] Ongena, M., Jacques, P. (2008): Bacillus lipopeptides: versatile weapons for plant disease biocontrol. - Trends in Microbiology 16: 115-125.

[38] Palazzini, J., Groenenboom-de Haas, B., Torres, A., Köhl, J., Chulze, S. (2013): Biocontrol and population dynamics of Fusarium spp. on wheat stubble in Argentina. Plant Pathology 62: 859-866.

[39] Palazzini, J. M., Alberione, E., Torres, A., Donat, C., Köhl, J., Chulze, S. (2016): Biological control of Fusarium graminearum sensu stricto, causal agent of Fusarium head blight of wheat, using formulated antagonists under field conditions in Argentina. Biological Control 94: 56-61.

[40] Pérez-García, A., Romero, D., De Vicente, A. (2011): Plant protection and growth stimulation by microorganisms: biotechnological applications of Bacilli in agriculture. Current Opinion in Biotechnology 22: 187-193.

[41] Pestka, J. J. (2007): Deoxynivalenol: toxicity, mechanisms and animal health risks. Animal Feed Science and Technology 137: 283-298.

[42] Pestka, J. J., Smolinski, A. T. (2005): Deoxynivalenol: toxicology and potential effects on humans. - Journal of Toxicology and Environmental Health, Part B 8: 39-69.

[43] Pitchen, R. (2002): The medicinal chemistry of the cyclic dipeptides cyclo (Met-Met) and cyclo (Met-Gly). - MSc Thesis, Faculty of Health Sciences, University of Port Elisabeth.

[44] Roitman, J. N., Mahoney, N. E., Janisiewicz, W. J. (1990): Production and composition of phenylpyrrole metabolites prodcued by Pseudomonas cepacia. - Applied Microbiology and Biotechnology 34: 381-386.

[45] Rudi, A., Kashman, Y., Benayahu, Y., Schleyer, M. (1994): Amino acid derivatives from the marine sponge Jaspis digonoxea. - Journal of Natural Products 57: 829-832.

[46] Sansinenea, E., Salazar, F., Jiménez, J., Mendoza, Á., Ortiz, A. (2016): Diketopiperazines derivatives isolated from Bacillus thuringiensis and Bacillus endophyticus, establishment of their configuration by X-ray and their synthesis. - Tetrahedron Letters 57: 2604-2607.

[47] Simpfendorfer, S., Brettell, R., Nicol, J. (2012): Inter-row sowing reduces crown rot in winter cereals. - First International Crown Rot Workshop for Wheat Improvement'. Narrabri. Organising Committee of the 1st International Crown Rot Workshop.

[48] Sinha, S., Srivastava, R., De Clercq, E., Singh, R. K. (2004): Synthesis and antiviral properties of arabino and ribonucleosides of 1: 3-Dideazaadenine, 4-Nitro-1: 3-dideazaadenine and Diketopiperazine. - Nucleosides, Nucleotides and Nucleic Acids 23: $1815-1824$. 
[49] Smiley, R. W., Gourlie, J. A., Easley, S. A., Patterson, L.-M. (2005a): Pathogenicity of fungi associated with the wheat crown rot complex in Oregon and Washington. - Plant Disease 89: 949-957.

[50] Smiley, R. W., Gourlie, J. A., Easley, S. A., Patterson, L.-M., Whittaker, R. G. (2005b): Crop damage estimates for crown rot of wheat and barley in the Pacific Northwest. Plant Disease 89: 595-604.

[51] Sopheareth, M., Chan, S., Naing, K. W., Lee, Y. S., Hyun, H. N., Kim, Y. C., Kim, K. Y. (2013): Biocontrol of Late Blight (Phytophthora capsici) disease and growth promotion of pepper by Burkholderia cepacia MPC-7. - The Plant Pathology Journal 29: 67-76.

[52] Stabb, E. V., Jacobson, L. M., Handelsman, J. (1994): Zwittermicin A-producing strains of Bacillus cereus from diverse soils. - Applied and Environmental Microbiology 60: 4404-4412.

[53] Ström, K., Sjögren, J., Broberg, A., Schnürer, J. (2002): Lactobacillus plantarum MiLAB 393 produces the antifungal cyclic dipeptides cyclo (L-Phe-L-Pro) and cyclo (L-Phetrans-4-OH-L-Pro) and 3-phenyllactic acid. - Applied and Environmental Microbiology 68: 4322-4327.

[54] Tanaka, K., Ishihara, A., Nakajima, H. (2014): Isolation of anteiso-C17, iso-C17, isoC16, and iso-C15 Bacillomycin D from Bacillus amyloliquefaciens SD-32 and their antifungal activities against plant pathogens. - Journal of Agricultural and Food Chemistry 62(7): 1469-1476.

[55] Vanittanakom, N., Loeffler, W., Koch, U., Jung, G. (1986): Fengycin-a novel antifungal lipopeptide antibiotic produced by Bacillus subtilis F-29-3. - The Journal of Antibiotics 39: 888-901.

[56] Wang, L.-Y., Xie, Y.-S., Cui, Y.-Y., Xu, J., He, W., Chen, H.-G., Guo, J.-H. (2015): Conjunctively screening of biocontrol agents (BCAs) against fusarium root rot and fusarium head blight caused by Fusarium graminearum. - Microbiological Research 177: 34-42.

[57] Xu, D., Deng, Y., Han, T., Jiang, L., Xi, P., Wang, Q., Jiang, Z., Gao, L. (2018): In vitro and in vivo effectiveness of phenolic compounds for the control of postharvest gray mold of table grapes. - Postharvest Biology and Technology 139: 106-114.

[58] Xue, A., Chen, Y., Sant'anna, S., Voldeng, H., Fedak, G., Savard, M., Längle, T., Zhang, J., Harman, G. (2014a): Efficacy of CLO-1 biofungicide in suppressing perithecial production by Gibberella zeae on crop residues. - Canadian Journal of Plant Pathology 36: 161-169.

[59] Xue, A. G., Chen, Y., Voldeng, H. D., Fedak, G., Savard, M. E., Längle, T., Zhang, J., Harman, G. E. (2014b): Concentration and cultivar effects on efficacy of CLO-1 biofungicide in controlling Fusarium head blight of wheat. - Biological Control 73: 2-7.

[60] Yan, P.-S., Song, Y., Sakuno, E., Nakajima, H., Nakagawa, H., Yabe, K. (2004): Cyclo (L-leucyl-L-prolyl) produced by Achromobacter xylosoxidans inhibits aflatoxin production by Aspergillus parasiticus. - Applied and Environmental Microbiology 70: 7466-7473.

[61] Zhao, L., Xu, Y., Lai, X.-H., Shan, C., Deng, Z., Ji, Y. (2015): Screening and characterization of endophytic Bacillus and Paenibacillus strains from medicinal plant Lonicera japonica for use as potential plant growth promoters. - Brazilian Journal of Microbiology 46: 977-989. 